\title{
JOGOS DA VERDADE. A NOVA GESTÃO PÚBLICA E A MODERNIZAÇÃO DO SISTEMA EDUCACIONAL ITALIANO
}

\author{
EMILIANO GRIMALDI* \\ Roberto Serpieri* \\ Danilo Taglietti*
}

\begin{abstract}
RESUMO: Nas últimas duas décadas, o sistema educacional italiano vem vivenciando um período de incontáveis reformas. Nesse sentido, a nova gestão pública (NGP), enquanto um discurso globalizante, assim como suas ideias e ferramentas, tem desempenhado um papel relevante. Este artigo busca propor uma leitura dinâmica tanto das transformaçóes como do papel do discurso da NGP e de suas ferramentas. Como pontos de partida analíticos, adotamos a construçáo de três problematizaçôes políticas e as soluçôes relacionadas, que se referem a: (a) a governança do sistema educacional; (b) a avaliação de sua qualidade; e (c) a regulamentação de seus profissionais. Tais problematizaçôes são interpretadas como os pontos de entrada da NGP e o cerne do processo de modernização do sistema educacional italiano. Em resumo, esses processos de aglutinação têm colocado em vigor práticas conflitantes e tensóes relacionados a: 1) a criação de quase-mercados no campo da educação; 2) reformulaçóes das relaçóes entre o Estado, as escolas, os profissionais e públicos de acordo com um objetivo racional e um modelo neogestionário; 3) a adoçáo de um processo progressivo, porém incansável, de privatização endógena da educação pública italiana.
\end{abstract}

Palavras-chave: Nova gestão pública; Problematização da política; Reforma da educação; Itália; Governamentalidade.

\section{GAMES OF TRUTH. NEW PUBLIC MANAGEMENT AND THE MODERNISATION OF THE ITALIAN EDUCATION SYSTEM}

ABSTRACT: In the last two decades, the Italian education system has lived a season of endless reforms. NPM as a globalising discourse and its ideas and tools have played out a relevant role. This article tries to propose a dynamic reading of both the transformations and the role played by NPM's discourse and tools. As analytical starting points we adopt the construction of three policy problematisations and the related

\footnotetext{
* Universidade Federico II, Departamento de Ciências Sociais. Nápoles, Itália. E-mail de contato: emiliano.grimaldi@unina.it.
} 
solutions, that concern: a) the governance of the Education system; b) the evaluation of its quality; and c) the regulation of its professionals. These policy problematisations are interpreted as the entry-points of NPM and the core of the modernising process of the Italian education system. To sum up, these assembling processes have enacted conflicting practices and tensions towards: a) the creation of quasi-markets in the field of education; b) the recasting of the relationship between the state, schools, professionals and publics according to a rational-goal and neomanagerialist model; c) the enactment of a progressive, but relentless, process of endogenous privatisation of the Italian public education.

Keywords: New public management; Policy problematisation; Education reform; Italy; Governmentality.

\section{JEUX DE VÉRITÉ. LA NOUVELLE GESTION PUBLIQUE ET LA MODERNISATION DU SYSTÈME ÉDUCATIF ITALIEN}

RÉSUMÉ: Au cours des deux dernières décennies, le système éducatif italien a connu une période d'innombrables réformes. Dans ce sens, la NGP en tant qu'un discours globalisant, comme ses idées et outils, a joué un rôle important. Ce document vise à proposer une lecture dynamique des transformations bien que l'importance du rôle du discours de la NGP (nouvelle gestion publique) et de ses outils. Comme points de départ analytiques, on a adopté la construction de trois problématisations politiques et les solutions concernées, qui se rapportent à: (a) la gouvernance du système éducatif; (b) l'évaluation de sa qualité; et (c) la réglementation de ses professionnels. Ces problématisations sont interprétées comme les points d'entrée de la NGP et le noyau du processus de modernisation du système éducatif italien. Bref, ces procédés de liaison ont mis en place des pratiques et des tensions contradictoires liées à: a) la création de quasi-marchés dans l'éducation; b) la reformulation des relations entre l'État, les écoles, les professionnels et le public en conformité avec un objectif rationnel et un modèle néogestionnaire; c) l'adoption d'un processus graduel, mais implacable, de privatisation endogène de l'éducation publique italienne.

Mots-clés: Nouvelle gestion publique; Problématisation de la politique; Réforme de l'éducation; Italie.

\section{Introdução}

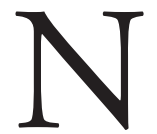

as últimas duas décadas, o sistema educacional italiano tem vivenciado um período de infinitas reformas. O ponto de partida deste processo de modernização se dá com a Reforma de Autonomia das Escolas, em 1997, que, por sua vez, fazia parte de uma ampla reformulação de toda a administração pública italiana. ${ }^{1}$ (ONGARO, 2009). 
Desde então, uma série incessante de leis, regulamentaçóes, reformas curriculares, programas políticos e experimentaçôes têm tentado alterar a configuração welfarista (de bem-estar social) do sistema educacional, que tem sido problematizado como sendo ineficaz e incapaz de responder aos desafios educacionais e sociais contemporâneos. Se a Autonomia das Escolas foi inicialmente enquadrada dentro de um discurso de "terceira via", que valorizava os potenciais democráticos do "local", ano após ano o neoliberalismo, neogerencialismo e neoconservadorismo vêm crescentemente se tornado discursos influentes no sentido de moldar o projeto de modernização do sistema educacional italiano.

A nova gestão pública (NGP) como um discurso, bem como suas ideias e ferramentas (HOOD, 1991; POLLITT; BOUCKAERT, 2011) desempenharam um papel relevante nesse período de reformas, atuando como um referencial inspirador e legitimador, e também como veículos para mudanças em toda a administração pública italiana e na governança do sistema educacional italiano.

Quatro trajetórias políticas são comumente identificadas para se delinear a entrada da NGP na administração pública a partir do início dos anos 1990:

- Um deslocamento gradual na organização do setor público em direção à descentralizaçáo, autonomia, diferenciação nos esquemas organizacionais e a introdução de mecanismos mercadológicos para a provisão de financiamento;

- O deslocamento de uma responsabilidade fiscal orientada por insumos para formas limitadas de sistema orçamentário baseado na responsabilidade na gestão financeira de organizaçóes públicas, aliado à introdução irregular de sistemas contábeis;

- A introdução de tecnologias para auditoria e mensuração de desempenho, com controles ex-post que tem (apenas parcialmente) substituído os controles ex-ante;

- Uma profunda alteração na gestão de recursos humanos, que tem sido cada vez mais associada ao desempenho, responsabilidade por resultados e esquemas de incentivo. (BELLÉ; ONGARO, 2014, p. 386-87)

Os resultados da reforma são extremamente controversos. A Itália é geralmente apresentada na literatura da NGP como uma 'retardatária' (KICKERT, 2007), uma variação sulista de um estado napoleônico onde as reformas da NGP falharam e o quadro legalista tem resistido e exercido uma capacidade significativa em neutralizar os princípios e a racionalidade da NGP. (PAINTERS; PETERS, 2010) O legalismo, a resistência a mudanças por parte do setor público, o clientelismo, a politização e o 'familismo' são seletivamente debatidos como fatores que explicam a tão chamada "lacuna da implementação". Neste cenário, a educação é retratada como um setor público que, diferentemente da saúde, por exemplo, permaneceu "amplamente intocada pelas massivas reformas da NGP" e tem visto 
apenas "algumas medidas inspiradas na NGP, como formas de empresarialização e gerencialização”. (ONGARO; VALOTTI, 2008, p. 384; 387)

Concentrando-nos no campo da educação e buscando observar atentamente os processos e nuances de mudança, os compromissos, mediações e recontextualização(çôes), buscaremos propor uma leitura mais dinâmica e complexa tanto das transformaçóes em jogo no campo da educação quanto do papel que o discurso e as ferramentas da NGP vêm desempenhando.

O artigo será desenvolvido adotando, como pontos de partida analíticos, a construção da problematização (FOUCAULT, 1977) de três políticas públicas e as soluçóes relacionadas, que dizem respeito à governança do sistema educacional, a avaliação de sua qualidade e a regulamentação de seus profissionais. Brevemente resumidas na Tabela 1 , tais problematizaçóes representam os pontos de entrada da NGP e o cerne do processo de modernizaçáo do sistema educacional italiano.

\section{Tabela 1}

A NGP e a modernização do sistema educacional italiano

Problematização de três políticas

\begin{tabular}{|c|c|c|c|}
\hline Tópico & Problemas da política & Soluções políticas & Eventos chave \\
\hline \multirow[b]{2}{*}{ Governança } & \multirow[b]{2}{*}{$\begin{array}{l}\text { O modelo centralizado e bureau- } \\
\text { professional [1] de regulação produz } \\
\text { organizações rígidas, ineficazes e } \\
\text { autorreferenciais }\end{array}$} & $\begin{array}{l}\text { Autonomia para as escolas e } \\
\text { descentralização como uma estratégia } \\
\text { para a desagregação }\end{array}$ & $\begin{array}{l}\text { 1992-1995 Legislação sobre a gestão } \\
\text { financeira e de servidores publicose } \\
\text { privatizações }\end{array}$ \\
\hline & & $\begin{array}{l}\text { A mescla entre autonomia, } \\
\text { responsabilização (accountability), } \\
\text { técnicas de gestão do setor privado e } \\
\text { concorrência podem atuar como } \\
\text { estímulo para a eficiência, eficácia e } \\
\text { aprimoramento (melhoria) }\end{array}$ & $\begin{array}{l}\text { Lei 59/1997; L. Decreto 112/1998; L. } \\
\text { Decreto 275/1999; Reforma } \\
\text { Constitucional de 2001; Autonomia das } \\
\text { escolas; descentralização; escolha da } \\
\text { escola; tamanho da escola }\end{array}$ \\
\hline \multirow{5}{*}{ Avaliação } & \multirow[t]{2}{*}{$\begin{array}{l}\text { O sistema educacional italiano é ineficaz } \\
\text { e possui baixo desempenho, conforme } \\
\text { evidenciam os resultados de testes } \\
\text { internacionais (PISA; TIMSS; IEA) }\end{array}$} & $\begin{array}{l}\text { Colocar maior ênfase no controle dos } \\
\text { resultados, por meio do } \\
\text { estabelecimento de um sistema de } \\
\text { avaliação escolar nacional }\end{array}$ & $\begin{array}{l}\text { 1999: Criação do INVALSI (Instituto } \\
\text { para a Avaliação do Sistema } \\
\text { Educacional) }\end{array}$ \\
\hline & & & 2000: O choque do PISA \\
\hline & $\begin{array}{l}\text { O sistema educacional italiano não } \\
\text { possui um sistema de mensuração } \\
\text { objetivo para avaliar seus resultados e } \\
\text { qualidade }\end{array}$ & $\begin{array}{l}\text { Padronização e gestão de } \\
\text { desempenho como alavancadores para } \\
\text { a melhoria nos resultados }\end{array}$ & 2007: Quaderno bianco \\
\hline & & & 2008: Testes nacionais do INVALSI \\
\hline & & & $\begin{array}{l}\text { 2013: Implantação do Sistema de } \\
\text { Avaliação Nacional }\end{array}$ \\
\hline \multirow{4}{*}{ Profissões } & \multirow{4}{*}{$\begin{array}{l}\text { Os profissionais do setor público são } \\
\text { autorreferenciais e não são } \\
\text { comprometidos com o aperfeiçoamento } \\
\text { devido à falta de controle e incentivos }\end{array}$} & \multirow{4}{*}{$\begin{array}{l}\text { Colocar as mãos na gestão } \\
\text { profissional por meio de : a) a } \\
\text { reconfiguração do ethos público dos } \\
\text { profissionais de acordo com os valores } \\
\text { do setor privado; b) a introdução de } \\
\text { tecnologias de gestão de desempenho; } \\
\text { e c) a instauração de um sistema de } \\
\text { recompensas e sanções }\end{array}$} & $\begin{array}{l}\text { 1999: Os diretores como funcionários } \\
\text { públicos de alto nível }\end{array}$ \\
\hline & & & $\begin{array}{l}\text { 2003-2010: Pilotos para a avaliação de } \\
\text { diretores }\end{array}$ \\
\hline & & & $\begin{array}{l}\text { 2010-2011: Piloto para avaliar os } \\
\text { professores }\end{array}$ \\
\hline & & & 2013: Piloto para avaliar as escolas \\
\hline
\end{tabular}

Nota: [1] N.T.: De acordo com Tomlinson, em Educational Management: Major Themes in Education (2013, p. 422), o bureau-professionalism se caracteriza por vinculos com valores profissionais, do serviço público, centrados no cliente. 
Discutiremos como as problematizaçôes apresentadas na Tabela 1 têm sido traduzidas em políticas públicas e como a NGP adentrou o sistema educacional italiano e tem sido recontextualizada. Para cada problematização, formularemos nosso argumento, apresentando as principais heranças que influenciam e flexionam a inserção das receitas da política da NGP no espaço nacional e os processos pelos quais isso está ocorrendo. A conclusão fornecerá uma discussão acerca dos efeitos das reformas da NGP (aqui compreendidas como mudanças epistêmicas, tecnológicas e éticas), bem como a produçáo de tensóes, surpresas e paradoxos.

\section{A modernização da governança educacional por meio de uma estratégia de desagregação}

O início dos anos 1990 representa um ponto de virada chave na elaboração de políticas públicas na Itália. Uma crise política dramática combinada à crise econômica e as pressóes oriundas da construção em andamento da União Europeia (redução de despesas, modernização, maior eficiência) criaram as condiçóes institucionais para o questionamento da configuração burocrática e centralista da administração e serviços públicos italianos.

De 1992 a 1995, três governos técnicos introduziram as primeiras regulamentaçóes sobre a gestão financeira das organizações públicas, privatizaçóes e gestão de servidores públicos, nas quais a influência exercida pelas ideias e ferramentas da NGP tornou-se evidente. Esta temporada política assiste, enquanto protagonistas, os técnicos (principalmente economistas) oriundos do Banco da Itália e a progressiva intensificação das conexóes entre os políticos italianos e a União Europeia (UE), o Banco Central Europeu e os circuitos de expertise da OCDE (MARTENS et al., 2007) que estavam apoiando as medidas da NGP como estratégias de política pública a fim de modernizar as administrações públicas e os sistemas de proteção social por toda a Europa. (BERTOZZI; GRAZIANO, 2004)

No debate político, a necessidade de reformar a governança da administração pública italiana tornou-se uma pressuposição irrefutável. Suas características napoleônicas (legalismo, centralismo, burocracia) estavam sob ataque como as causas da ineficácia e ineficiência. A NGP forneceu o referencial discursivo, assim como as ferramentas, para 'moldar' uma solução política. O sistema educacional estava incluído no debate como parte da administração pública ineficaz, embora tivesse sido parcialmente excluído das primeiras reformas com base no reconhecimento de seu caráter e configuração peculiares (um campo bureau-professional; um serviço inerentemente público) e devido a diversas resistências (sindicatos, administraçóes e partidos políticos de esquerda). 
No final dos anos 1990, contudo, graças às pressóes da OCDE, a reforma da governança do sistema educacional tornou-se uma prioridade, com base no argumento de que sua forma de regulação centralizada e bureau-professional produzia organizaçóes rígidas, ineficazes e autorreferenciais que não eram: a) capazes de interpretar e responder às necessidades educacionais de economia de conhecimento, mercados de trabalho globais e competitividade global, comunidades locais e alunos; b) eficazes na promoção da qualidade do capital humano; c) comprometidas com o aprimoramento/melhorias. A quebra do sistema burocrático e hierárquico em organizaçóes independentes, atuando em um ambiente descentralizado, foi identificada como uma estratégia de desagregação para modernizar o sistema, torná-lo mais eficiente e responsivo às necessidades da sociedade e, por fim, para elevar seu desempenho. Numa virada ortodoxa da NGP, a mescla entre autonomia, responsabilização (prestação de contas), técnicas de gestão do setor privado, concorrência (imitativa) e um sistema de incentivos foi mencionada como estímulo para a eficiência, eficácia e aprimoramento.

É neste cenário, então, que a Lei 59/1997 introduziu a autonomia das escolas como uma inovação no desenho organizacional do sistema educacional de acordo com o modelo de gestão local, dentro de uma ampla tendência em direção à descentralização/delegação de competências aos governos regionais e locais (ver o Decreto 112/98 sobre a delegação e o Decreto 127/97 sobre a simplificação administrativa). (ONGARO, 2009, p. 124)

Antes de 1997 o sistema educacional italiano era altamente centralizado. As relações de governança e a formulação de políticas ondulavam pelas hierarquias e o currículo nacional era definido centralmente. Os governos locais possuíam voz limitada na elaboração de políticas educacionais no âmbito local. Em tal sistema, a mudança foi gerada por meio de legislação nacional, padróes e procedimentos de insumo ${ }^{2}$, ao passo que a avaliação e os mecanismos de controle eram formais e principalmente focados nos insumos (recursos). (LANDRI, 2009) Dentro deste cenário, grande autonomia foi reconhecida para diretores e professores dentro de seu 'espaço profissional' (ensino, propostas para o currículo nacional, avaliação). (SERPIERI, 2009)

A reforma de 1997 altera profundamente a identidade e funcionamento organizacional das escolas, concedendo-lhes mais espaço para manobras em questões financeiras, organizacionais e educacionais (embora o recrutamento de pessoal tenha permanecido como competência do Estado). As escolas ficaram encarregadas de delinear seu plano educacional anual (POF), planejar projetos escolares individuais/distintivos, definir as prioridades curriculares locais e planejar, ao menos em parte, sua organização interna (ver o Decreto 275/99). A influência do discurso da Terceira Via é particularmente evidente neste estágio da reforma, graças também à intensificação da conexão entre a coalizão centro-esquerda italiana e os gurus políticos do New Labour (ex.: M. Barber). 
Na verdade, em uma maneira própria à NGP, as escolas autônomas devem se autogovernar de acordo com as lógicas de gestão do setor privado (eficiência, eficácia e empreendedorismo). Os diretores assumem um papel de gestão e são definidos como sendo responsáveis por seus resultados. $\mathrm{Na}$ mesma linha, as escolas são convidadas a construir parcerias com outros atores públicos e privados, a fim de perseguir sua missão educacional e interagir com as autoridades e comunidades locais. Mecanismos de financiamento adicionais são introduzidos como incentivos para sustentar tais alteraçóes (isto é, lances de fundos da UE atuam como um veículo para o estabelecimento de parcerias público/privadas como um arranjo institucional obrigatório para as escolas). Ao mesmo tempo, em nível retórico, os potenciais democráticos da autonomia das escolas são amplamente enfatizados. Parcerias e redes são explicitamente identificadas como canais potenciais através dos quais é possível captar recursos públicos ou privados adicionais e enriquecer a oferta educacional. Por fim, grande ênfase é colocada na questão da responsabilização, sublinhando a estreita relação entre autonomia, liberdade, avaliação externa e responsabilidade em relação às partes envolvidas.

Esta forma peculiar de autonomia das escolas foi designada dentro do quadro de uma descentralização branda. Na verdade, o Ministério da Educação mantém

[...] o controle sobre a governança geral do sistema, o delinea-
mento dos princípios gerais para a educação e o estabelecimento
de níveis mínimos de desempenho, além de definir o currículo
nacional e gerir os recursos financeiros e profissionais por meio
de seus escritórios administrativos regionais [...]. (GRIMALDI;
SERPIERI, 2014, p. 125)

Os governos regionais e locais são encarregados das competências relevantes no que concerne ao planejamento territorial (por exemplo, abrir, fechar e fundir escolas) e os prédios escolares (ver o Decreto 112/98).

A autonomia das escolas italianas é amplamente considerada como uma das mais limitadas em comparação com sistemas realmente descentralizados. (EURYDICE, 2007; VITERITTI, 2009) Especialistas descrevem uma reforma falida, um sistema "bloqueado" que absorveu os potenciais inovadores da autonomia das escolas e gestáo local. Além do mais, a literatura sobre a NGP apresenta a educação como um campo institucional onde as formas de gestão foram introduzidas, "[...] porém, com um escopo limitado e sem um recurso massivo a outros mecanismos, como os mecanismos de mercado [...]”. (BELLÉ; ONGARO, 2014, p. 384)

Indubitavelmente, a década após a reforma da autonomia das escolas de 1997 foi caracterizada como um processo de recentralização no campo da educação. 
Os governos de direita de Berlusconi [N.E.: Silvio Berlusconi, Primeiro-ministro da Itália, em diversos períodos entre os anos de 1994 a 2011) de certa forma enfraqueceram a autonomia da escola, deixando incompletas tanto sua regulamentaçáo como a transferência de competências (por exemplo, a gestão de recursos humanos e a autonomia financeira), alterando a agenda política (por exemplo, mudando a atenção para reformas curriculares e, mais tarde, para a avaliação) e criando incertezas em torno da real possibilidade de se reforçar a autonomia da escola por meio de uma política de austeridade. Curiosamente, a agenda neocentralista foi o ponto de convergência paradoxal para uma coalizão heterogênea de grupos de interesses, que incluíram: a) neoconservadores, que estavam interessados no controle do Estado sobre a educação; b) partidos de esquerda e sindicatos, que estavam preocupados com os riscos de mercantilização e polarização do sistema educacional; c) burocratas centrais e locais, que desejavam preservar seus poderes.

Argumentamos aqui que, se olharmos mais atentamente para o caso italiano, a característica distintiva desta trajetória de modernização da governança educacional pode ser identificada na presença de várias correntes e forças contrárias, cuja interação produz um processo peculiar de recontextualização da receita de política de desagregação da NGP (gestão local somada à descentralização, mercantilização/concorrência e parceria dá-nos maior eficiência).

A reforma de 1997 representa, na verdade, uma fratura institucional onde foram criadas as condições para a entrada permanente de algumas das características peculiares da NGP no sistema educacional italiano e alguns processos profundos de mudança foram postos em ação. Neste artigo nos centraremos, em particular, na abertura de espaços para quase-mercados. Políticas neocentralistas e a forte oposição por parte do "bloco welfarista" (sindicatos, partidos de esquerda, associaçóes de professores e movimentos estudantis) limitaram parcialmente tanto a explosão da dinâmica competitiva entre as escolas e os sistemas locais, mas também, de alguma forma, inibiram a exploração do potencial democrático e ascendente inerente a uma compreensão colaborativa da autonomia da escola. Nossa tese, contudo, é que a estratégia de desagregação posta em ação por meio da reforma da autonomia abriu alguns espaços para o desenvolvimento de quase-mercados locais no sistema educacional italiano. (BENADUSI; CONSOLI, 2004; GRIMALDI; SERPIERI, 2010)

Este é o efeito combinado, argumentamos, de algumas características peculiares da reforma de 1997. Em primeiro lugar, a micropolítica das escolas foi impulsionada em direção a um modelo gestionário (BENADUSI; CONSOLI, 2004), por meio de pressóes discursivas sobre as escolas e diretores no sentido de que deveriam se tornar organizaçóes e profissionais ${ }^{3}$ gestionários e empreendedores. Essas pressóes foram reforçadas na última década pelas políticas de austeridade que forçaram as escolas a se 'promoverem' para encontrar fundos adicionais nos 
mercados locais a fim de aumentar sua oferta educacional e se tornarem mais atrativas.

Em segundo lugar, esta tendência em direção à configuração de organizaçóes orientadas ao mercado tem sido sustentada por duas outras alteraçóes legislativas. $\mathrm{Na}$ verdade, o problema da atratividade tornou-se particularmente relevante para as escolas italianas desde 1997 porque, por um lado, a reforma da autonomia desregulou a escolha da escola pelas famílias (antes de 1997, as famílias podiam escolher dentre um limitado número de escolas, dependendo do seu local de residência). Por outro lado, a reforma introduziu um número mínimo de alunos para que uma escola fosse considerada autônoma, ordenando o fechamento ou a fusão de escolas que não atendessem a esse número mínimo (tamanho da escola). Além disso, esses processos de quase-mercantilização também foram reforçados em algumas áreas por políticas regionais que promoveram os esquemas de voucher (como no caso de Lumbardy, por exemplo).

Como resultado, à sombra da hierarquia, essas mudanças implicaram a abertura de novas arenas de delegação em que as escolas se tornaram cada vez mais empresariais e começaram a competir por alunos, tentando forjar uma "boa reputação" para si. Cada vez mais, seu sucesso e atratividade dependem de sua capacidade de angariar fundos adicionais (alguns comentadores têm usado, numa visada negativa, o termo "fábricas de projetos" para descrever as escolas italianas contemporâneas). O empreendedorismo, à sombra da hierarquia, significa o estabelecimento de relaçôes com os financiadores públicos, especialmente os governos locais, mas também significa a abertura de novos espaços para parcerias público/ privadas. Um papel chave, nesse sentido, é desempenhado pela ampla difusão dos esquemas de fundos públicos (principalmente a UE, mas também fundos locais e do Estado) que tornaram a parceria público/privada uma forma organizacional obrigatória para as escolas que querem ter acesso a tais financiamentos.

No entanto, uma compreensão profunda do real impacto desses processos de mudança e a entidade real dos impulsos em direção a uma encoberta quase-mercantilização da governança educacional requer uma leitura sistêmica dos entrelaçamentos entre as mudanças na governança (autonomia da escola e descentralização) e as transformaçóes dos mecanismos de controle (avaliação e gestão do desempenho) e a relação entre o Estado, as escolas e seus profissionais.

\section{O novo espetáculo da avaliação. Curando um sistema ineficaz por meio de padrões}

Uma segunda trajetória política na qual a Nova Gestão Pública desempenhou um papel relevante na transformação do sistema educacional italiano é o 
estabelecimento de um sistema nacional de avaliação baseado em padröes. Poucos anos após a reforma da Autonomia, a Itália foi atingida pelo choque do PISA (e TIMSS e IEA), que representaram o sistema educacional italiano como sendo ineficaz e tendo baixo desempenho, colocando o problema de sua qualidade no centro da agenda. Além disso, a premência era então a necessidade de preencher um vazio, a falta de qualquer medida objetiva para avaliar o resultado e a qualidade do sistema educacional italiano (e de suas unidades e profissionais), sendo este o legado de um mundo educacional autorreferencial e "não-moderno".

A solução política fora identificada, em um claro estilo da NGP, ao se colocar mais ênfase no controle de resultados, em contraste com o legado napoleônico de controle de insumos. O estabelecimento de um sistema de avaliação escolar nacional foi requerido, a fim de fornecer mensuraçóes objetivas para avaliar os resultados e a qualidade educacional, juntamente com as ferramentas para a promulgaçáo das tecnologias de "como fazer" da NGP, tais como gestâo de desempenho e melhoria organizacional (ou seja, a construção da infraestrutura informacional para a gestáo das escolas).

Os eventos chave nesta trajetória política são:

- A criação de um Instituto Nacional para a Avaliação das Escolas (Invalsi) no início dos anos 2000 e o lançamento de Testes Nacionais dos Alunos nas disciplinas de Italiano e Matemática, que se tornaram obrigatórios em 2008;

- A publicação do Quaderno Bianco della Scuola (O Livro Branco da Escola) em 2007, no qual uma problematização, inspirada na NGP, do "estado de saúde" do Sistema Educacional Italiano é apresentado, e uma agenda de modernização do sistema é delineada, com base na fórmula mágica padronização mais avaliação mais concorrência mais melhorias igual a melhores resultados;

- A progressiva centralidade dos resultados do Invalsi como um ponto de passagem obrigatório para formular qualquer tipo de julgamento acerca da qualidade dos processos educacionais (2008-2012);

- O lançamento de uma longa série de tentativas experimentais para introduzir novos dispositivos para avaliar os diretores, professores e escolas com base nos resultados de testes, mensuraçôes objetivas, autoavaliação regulada externamente e o uso de comparaçáo como um expediente para gerar compromisso com o aperfeiçoamento (2000-2013);

- A maior transparência pública dada aos resultados dos testes no website do Ministério, em nome do princípio sagrado de transparência e responsabilização devido aos pais;

- A controversa implantação, em 2013, de um Sistema Nacional de Avaliação, um sistema tripartite combinando: (a) testes nacionais padronizados; (b) um corpo nacional de inspetores, que devem conduzir os processos de inspeção; e (c) o deslocamento de peritos ou especialistas, conhecimentos e metodologias para apoiar as escolas que se engajam em processos de aprimoramento, coordenados por uma agência vinculada ao Ministério, o Instituto Nacional para Pesquisa e Inovação Educacional (Indire). (LANDRI, 2014) 
A adoção desta nova agenda de avaliação foi possível graças ao empréstimo (do discurso da UE e da OCDE) de um conjunto de movimentos discursivos que alteraram a episteme da educação e definiram os objetos e subjetividades da educação em um campo de visibilidade enquadrado pela comparação. Primeiramente, nós testemunhamos a aceitação da lógica da mensuração, que esposa as lógicas da NGP no que tange à reprodução, no âmbito da escola, de um modo de governar a conduta das escolas e de seus profissionais caracterizado como uma "condução à distância". A economia e as estatísticas atuam, na prática, como o novo conhecimento para se compreender e tornar inteligíveis os processos educacionais. Em segundo lugar, a lógica do contratualismo vem para regular as relaçóes entre o Estado, as unidades públicas e organizacionais e os sujeitos-profissionais do sistema educacional como um contrato de compra baseado em resultados mensuráveis. As tarefas, as obrigaçóes, os objetivos a serem perseguidos e as tecnologias educacionais a serem empregadas são cada vez mais especificados por autoridades externas que, a despeito da retórica, estipulam os objetivos e avaliam os resultados independentemente dos contextos, backgrounds, alunos, estórias e contingências, neutralizando e inibindo, na verdade, qualquer forma de julgamento profissional. Um modelo contratual deste tipo implicitamente rejeita o segundo pilar do profissionalismo welfarista, ou seja, a confiança, e transmite uma visão das profissóes como um grupo com interesses próprios, cujo trabalho precisa ser organizado em uma linha de gestão e então monitorado, para que a qualidade dos serviços seja garantida. A agência moral dos profissionais da educação, enquanto indivíduos trabalhando para o "interesse público" ou para o "bem público", permanece não reconhecida e, pior ainda, é negada. (GRIMALDI; SERPIERI, 2013, p. 329)

Em terceiro lugar, as novas práticas de controle externo com base em padróes são, na verdade, moldadas por um discurso de fracasso. Tal discurso performativo subjetiva os indivíduos e as organizaçóes como tendo tendência ao fracasso, por intermédio de um deslocamento de uma complexa matriz de sançóes e ameaças. (NEWMAN, 2001, p. 91) Tal discurso frequentemente coopta a ideia democrática e em voga de "apoiar os mais fracos e fazê-los melhorar". Não obstante, na verdade, tal discurso possui vários efeitos polarizadores e controversos, como a divisão dos grupos profissionais em heróis e perdedores, sobrecarregando os profissionais com expectativas "impossíveis de atingir" em relação à sua capacidade de resolução de problemas educacionais complexos (e estruturalmente enraizados) e forçando-os a se fabricar enquanto "bons executores".

\section{Reestruturando e subjetivando as profissões docentes}

O estilo italiano para a NGP, como vimos, implicou em alteraçôes relevantes em termos da governança e avaliação das escolas, mas também atuou sobre 
os corpos (e almas) das profissóes docentes e dos legados do bureau-professionalism. Uma nova "episteme do serviço público" (BALL, 2008, p. 51) foi necessária para fazer face às práticas em processo de transformação e às "[...] formas em transição do profissionalismo docente [e do diretor] [que vão desde o]: tradicional, de gestão, colaborativo e democrático [...]" (WHITTY, 2008) e ao confronto das vidas profissionais com novos e conflitantes dilemas e "questóes éticas". (LUNT, 2008) A NGP da educação italiana tentou, então, minar as formas tradicionais de autonomia profissional e os arranjos democráticos de colegialidade por meio de consagradas, e geralmente contraditórias, trajetórias de políticas de reestruturação. Além disso, novos regimes de conhecimento e relaçóes de poder produziram efeitos nas (mas também foram produzidos por) novas subjetivaçóes. No tópico a seguir discutiremos esse tema no que tange a professores e diretores.

Após a reforma da autonomia das escolas, a profissão de diretor foi (re) construída como uma aposta promissora de transformação e de aperfeiçoamento: da mesma forma que em outros sistemas educacionais reestruturados, o "expediente" de liderança, com suas ideias relacionadas como gestão e empreendedorismo (GUNTER, 2012; HALL, 2013) atuou, na verdade, como o principal dispositivo político. (GRIMALDI; SERPIERI, 2014)

Ao mesmo tempo, durante os últimos 30 anos, e mais fortemente na última década, a profissão docente tem sido atingida tanto pelos significativos esforços de redução de custos e cortes de gastos por um lado, quanto, em termos de seus valores éticos e perfis profissionais, sendo acusados de ineficácia (quando não de "preguiçosos"), e como tendo pouca competência e baixo compromisso.

\section{O diretor híbrido}

Em 2000, o Ministro da Educação da Itália, Luigi Berlinguer, explicou claramente a lógica subjacente ao redesenho do perfil do diretor escolar italiano como um complemento e apoio necessário à reforma de Autonomia das Escolas de 1997:

A estrutura centralizadora tem sobrecarregado os dirigentes escolares com deveres e obrigaçóes burocráticas, ao passo que a escola autônoma precisa de dirigentes escolares que sejam capazes de assumir responsabilidades, planejar e implantar novos projetos e atividades, organizar e estimular o trabalho dos professores, ouvir os alunos, envolver as famílias, gerir os recursos e interagir com atores externos. [La struttura centralistica ha oberato $i$ dirigenti scolastici con compiti ed obblighi di natura burocratica, mentre la scuola autonoma ha bisogno di dirigenti scolastici che siano in grado di assumersi responsabilità, programmare ed implementare nuovi progetti ed attività, organizzare e stimolare il lavoro degli 
insegnanti, ascoltare gli studenti, coinvolgere le famiglie, gestire le risorse ed interagire con attori esterni.] (BERLINGUER, 2001, p. 111-112)

A solução política passa a ser colocar as mãos na gestão profissional por meio de: a) reformulação do ethos do profissional público de acordo com os valores do setor privado (aperfeiçoamento, competição, empreendedorismo, responsabilidade por resultados); b) introdução de tecnologias de gestão de desempenho; e c) implantação de um sistema de recompensas e sanções.

De forma semelhante ao que ocorreu em outros sistemas educacionais, a liderança se torna parte e dispositivo de um processo mais amplo de transmissão, para a escola, da responsabilidade pela qualidade e "melhoria" do desempenho. Desta forma, o dirigente como um gerente, foi identificado como o fomentador de mudanças para a promoção de melhorias, mesmo que, ainda hoje em dia, a autonomia financeira da escola, bem como a gestão de recursos humanos, continue a ser grandemente restrita pela regulação central, limitando o espaço para manobras a alguns "pequenos" arranjos e negociaçóes organizacionais. Da mesma forma, a governança da escola, traçada durante os anos 1970 com base nos princípios da participação profissional e democrática, permanece atualmente "intocada” pelas reformas, implicando a necessidade de o dirigente continuamente negociar o processo de tomada de decisóes interno. Por fim, o empreendedorismo representa um valor central que inspirou as tentativas de reconfigurar o papel externo da liderança, na medida em que os diretores foram identificados como atores-chave nas novas arenas educacionais locais que lhes foram delegadas e delineadas por meio da reforma.

Primeiro, foi-lhes pedido que estabelecessem relaçóes e um clima positivo com os governos locais e que prestassem contas às burocracias periféricas. Depois, os diretores deveriam explorar e tirar vantagem de parcerias e colaboraçóes com grupos institucionais, culturais, sociais e econômicos existentes na regiāo da escola. O novo diretor se tornou, potencialmente, um "empreendedor" com várias obrigaçóes. A fim de manter um número suficiente de alunos, ele precisa tornar a escola atrativa para os alunos, mas, principalmente para os pais. A perda de alunos significa menos professores, bem como o risco de perder o status de autonomia. Para evitar esses riscos, o diretor deve buscar enriquecer a oferta educacional da escola, captando fundos ou recursos adicionais para atividades extracurriculares. Como consequência, ele deve dedicar tempo considerável promovendo relaçóes externas com as autoridades locais e com outros atores públicos e privados. Em tal contexto, o desenvolvimento de habilidades empresariais se torna uma necessidade, enquanto a competição e um ethos orientado ao cliente se revelam como novos valores ocultos. (WHITTY, 2002) Isso poderia ser visto como um passo inicial de um processo de "privatização endógena" (BALL; YOUDELL, 2008) dentro do sistema escolar italiano. 
A hibridização é uma história de conflito em torno da questão polêmica da responsabilização profissional, onde as resistências e a luta contra o discurso da NGP se tornam fortemente visíveis. Faz mais de 10 anos, na verdade, que as tentativas de introduzir os novos dispositivos gestionários de responsabilização (gestão de desempenho, gestão por objetivos), juntamente com o controle legal-financeiro, típico do ambiente burocrático, têm falhado. A história da avaliação da liderança na Itália teria início em 1999, com a primeira hesitante e incerta tentativa, cuja tecnologia de avaliaçáo era principalmente baseada na autoavaliação e na definição, pelos próprios diretores, dos objetivos a serem perseguidos. (SERPIERI, 2009) Foi o Decreto 165/2001 que introduziu, ao menos formalmente, a lógica da gestão por objetivos e o princípio de "contratualismo" (YEATMAN, 1994, p. 110), provando a evidência da diminuição de confiança na escola e em seus grupos profissionais e, consequentemente, nas formas de autoavaliação. Consistente com as regras da NGP, o Decreto delineia um processo onde o Ministro negocia os objetivos a serem perseguidos diretamente com o diretor, substituindo o ethos da autorregulação profissional pela devida lógica econômica: ao passo que a confiança diminui, os profissionais são progressivamente reclassificados como agentes utilitaristas cujo oportunismo precisa ser limitado, introduzindo uma reversão da assimetria informacional a favor de parâmetros mensuráveis e calculáveis.

Nos anos seguintes, diferentes tentativas se sucedem e diferentes modelos são testados. Quanto mais as experiências falham, tanto mais é possível observar o estabelecimento progressivo e paradoxal da crença de que a escola precisa ser entregue a cuidados terapêuticos de uma liderança 'heroica', juntamente com a tendência geral que, em outro trabalho, definimos como a "virada diagnóstica". (GRIMALDI E SERPIERI, 2013) A liderança heroica é a mágica que pode garantir a realização efetiva de planos de melhoria, ao passo que a mensuração se torna cada vez mais urgente e premente. $\mathrm{O}$ último ato desta estória (mesmo que provisório) está representado no VALES 2012, uma tentativa ainda em andamento que surge após uma temporada intensa de políticas educacionais onde a atenção pareceu se deslocar da avaliação somente do diretor, para a de escolas e professores, dentro de um quadro mais amplo de implantação de um sistema de avaliação nacional.

\section{Os professores em número cada vez menor e tão confessantes quanto possível}

Não é fácil reconhecer como a Nova Gestão Pública afetou os professores na Itália porque, de certa forma, eles parecem ser imunes às pressóes gestionárias. Os diretores, na verdade, como discutimos acima, não têm poder para recrutar, avaliar ou despedir professores (embora isso esteja agora na agenda do governo) e apenas pouco espaço para manobras em relação a seu desenvolvimento profissional, devido ao montante muito limitado de recursos financeiros ad hoc. Enquanto 
líderes educacionais, eles estão restritos a contar com seu estilo "transformativo" ou "democrático" para estimular o compromisso e a participação dos professores.

De qualquer forma, é evidente que na Itália o "primeiro movimento" sobre a profissão docente implicou na redução de sua força de trabalho (desde o ano 2.000, o número de professores caiu de cerca de 820.000 para 720.000). É interessante observar como esta reduçáo é justificada não apenas em termos de cortes de gastos, mas também de um discurso neoconservador. No ensino fundamental, por exemplo, após 20 anos desde a reforma que promoveu a alteração de apenas um professor por sala para um time de três (algumas vezes quatro) por sala, o Ministro da Educação do último governo de centro-esquerda de Berlusconi, lançou uma campanha para voltarem atrás. O papel tradicional do "único mestre" foi, na verdade, apresentado como uma forma de assegurar um modelo pedagógico adequado para confrontar a fragmentação educacional e a "negligência" profissional. Ao mesmo tempo e, paradoxalmente, por intermédio de uma linguagem progressista, tem havido, durante os últimos anos, um movimento em direção à fusão de todas as "Necessidades Educacionais Especiais", com o intuito de reduzir custos. E, por fim, ano após ano, as escolas são forçadas a se fundir em uma escola maior, onde é possível reduzir custos (um diretor, menos papéis administrativos, professores em comum).

A NGP, contudo, também tem tentado salientar o clima moral da avaliação do professor, uma "batata quente" (BARZANÒ; GRIMALDI, 2013) no sistema educacional italiano, supondo que a mera proposição de tal avaliação provocaria a renúncia de Berlinguer, o Ministro da Educação de centro-esquerda que promoveu a Reforma da Autonomia das Escolas no final dos anos 1990. Embora tenhamos aqui uma estória semelhante, porém menos intensa, de tentativas fracassadas de introduzir dispositivos de avaliação, como no caso dos diretores, um clima moral para uma virada 'meritocrática' na profissão docente está se ampliando entre a opinião pública, os elaboradores de políticas públicas (tanto de partidos de direita quanto de centro-esquerda) e os grupos de agências, fundaçóes e peritos das mais variadas disciplinas e, cada vez mais, de campos não ligados à educação. Também neste caso os padróes nacionais de aprendizagem parecem atuar como um ponto de passagem obrigatório para forçar a política de avaliação no sentido de implantar algum tipo de dispositivo de "confissão" (FEJES; NICOLL, 2015) da NGP, que também torna os professores italianos 'culpados' e sujeitos ao aperfeiçoamento.

\section{Conclusão}

A entrada das ideias e tecnologias da Nova Gestão Pública no sistema educacional italiano não pode ser interpretada como uma trajetória política 
coerente e unitária. Pelo contrário, apresentamos as transformações complexas e multifacetadas que emergem como efeitos performativos da conjunção de discursos políticos diversos, novas tecnologias de governança e educacionais e procedimentos administrativos renovados, juntamente com a formação e a entrada em cena de novas subjetividades.

Ao invés de nos centrarmos nas resistências, fracassos e continuidades, tentamos destacar em que medida as ideias e tecnologias da NGP estão contribuindo para a lenta, porém implacável implantação de um novo regime de governança (DEAN, 2010) no campo da educação, isto é, a institucionalização de formas relativamente organizadas de direcionar a conduta dos sujeitos da educação (DEAN, 2010, p. 268-69) que se baseia em: a) a teoria do capital humano e economia da educação como as formas dominantes de racionalidade na educação; b) estatísticas, comparação e gestão de desempenho como a nova techne e os novos princípios de organização dos campos de visibilidade na educação (ROSE, 1999); c) privatização endógena (BALL; YOUDELL, 2008) e competição imitativa como o principal impulsionador no que tange à reconstrução de identidades, moralidades e agências na educação.

Em resumo, as três problematizações que abordamos e as soluções políticas relacionadas, fizeram emergir práticas conflitantes e tensões em relação a:

- A criação de quase-mercados no campo da educação;

- A reformulação da relação entre o Estado, as escolas, os profissionais e públicos, de acordo com um modelo de objetivos racionais e neogestionário (NEWMAN, 2001);

- A colocação em vigor de um processo progressivo, porém implacável, de privatização endógena da educação pública italiana.

A combinação entre a estratégia de desagregação da NGP e a alternância entre descentralização/desregulação e centralização/regulação central resultou em uma progressiva estratificação de um modo de governo hierárquico no campo da educação no qual as linhas coordenadas vertical e horizontal se combinam e se sobrepóem. (GRIMALDI, 2011) Embora o modo hierárquico de coordenação permaneça sendo o principal, o sistema está cada vez mais, e incansavelmente, adotando um modo plural de regulação/controle onde, paradoxalmente, o Estado continua a exercer um forte controle sobre os mecanismos de alocação de recursos e sobre a definição do currículo nacional, mas, ao mesmo tempo, está forjando para si o papel de um Estado avaliativo (NEAVE, 2012) que dirige à distância, por intermédio da padronização e do controle dos resultados. À sombra do estado avaliativo, as políticas de desregulação (escolha da escola, tamanho da escola e fusóes, fundos competitivos etc.) estão abrindo espaço para quase-mercados locais. 
Como um outro lado dessa virada avaliativa, juntamente com a propagação de dispositivos de padronização, algumas outras ferramentas de auto-avaliação foram lançadas. Como mais uma consequência dos paradoxos da NGP (HOOD; PETERS, 2004), a estratégia de descentralização tem sido contrabalançada pelo planejamento centralizado de um novo pan-óptico de avaliação, inspirado nos mitos de mensuração e transparência da NGP. Neste cenário, mesmo as ferramentas mais brandas, como aquelas autoavaliativas, estão restritas a uma lógica de extração de 'confissóes' (FEJES; NICOLL, 2015) por intermédio de grades rígidas e padronizadas propostas pelo Invalsi.

Uma área em que os efeitos performativos das ideias e tecnologias de avaliação da NGP são evidentes é na reformulação da relação entre o Estado, os profissionais e públicos (entendidos como os envolvidos/interessados). Nós argumentamos que um novo ambiente moral está pressionando as subjetividades dos diretores em direção a um regime 'contratualista' (GRIMALDI; SERPIERI, 2013), no qual eles são, cada vez mais, supostos a ser responsáveis por seus resultados. Isto, na verdade, não se aplica exatamente aos professores italianos, que se beneficiarão de um status welfarista ainda enraizado nas escolas e nos serviços públicos e que, em conjunto com os sindicatos, estáo mostrando uma capacidade significativa em resistir aos ataques da NGP à sua autonomia profissional e autorregulação.

Não obstante, as complexas e multifacetadas transformaçóes que descrevemos testemunham um processo em andamento de reaculturação do campo educacional italiano, onde as preocupaçóes com a eficácia, eficiência e empreendedorismo, gestão, responsabilidade, avaliação e aperfeiçoamento estão, cada vez mais, marginalizando, ocultando e cooptando as preocupaçóes com o bem-estar social como a igualdade, justiça social e cidadania democrática.

\section{Notas}

\section{Traduzido por Karin Quast}

2. N.T.: Aqui englobando os recursos humanos, recursos financeiros e materiais, aspectos relacionados à estrutura dos prédios, às variadas instalaçóes, mobiliário, equipamentos, aparelhos e seu funcionamento, remuneração dos profissionais, formação inicial e continuada, jornada de trabalho, fatores contextuais, dentre outros.

3. A nova ênfase na gestáo, responsabilidade e empreendedorismo coexistiam com o reconhecimento do fracasso do modelo participativo democrático da gestão escolar (na Itália, uma assembleia democrática de professores, liderada pelo diretor, gerencia a escola) estabelecido desde 1974. 


\section{Referências}

BALL, S. J. The Education Debate. Bristol: Polity Press, 2008.

BALL, S. J.; YOUDELL, D. Hidden Privatisation in Public Education. Brussels: Education International, 2008.

BARZANÒ, G.; GRIMALDI, E. Discourses of merit. The hot potato of teachers' evaluation in Italy. Journal of Education Policy, v. 28, n. 6, 2013, p. 767-791.

BELLÉ, N.; ONGARO, E. NPM, administrative reforms and public service motivation: improving the dialogue between research agendas. International Review of Administrative Sciences, v. 80, n. 2, 2014, p. 382-400.

BERLINGUER, L. La Nuova Scuola. Bari: Laterza, 2001

BENADUSI, L.; CONSOLI, F. (Eds.). La governance della scuola. Bologna: Il Mulino, 2004 .

BERTOZZI, F.; GRAZIANO, P. Italy's adaptation underexternal pressures: whose influence? In: ARMINGEON, K.; BEYELER, M. (Eds.). The OECD and European welfare states. Cheltenham: Edward Elgar Publishing, 2004, p. 169-182.

DEAN, M. Governmentality. Power and rule in modern society. 2. ed. London: Sage, 2010.

EURYDICE. School Autonomy in Europe. Policies and Measures. Brussells: Eurydice/European Commission, 2007.

FEJES, A.; NICOLL, K. (Eds.). Foucault and the Politics of Confession in Education. London: Routledge, 2015.

FOUCAULT, M. Language, counter-memory, practice: selected essays and interviews. New York: Cornell University Press, 1977. [Edited with an Introduction by Donald F. Bouchard. Transleted from the French by Donald F. Bouchar and Sherry Simon].

GRIMALDI, E. Governance and Heterarchy in Education. Enacting networks for schools innovation. Italian Journal of Sociology of Education, v. 8, n. 2, 2011, p. 114-150.

GRIMALDI, E.; SERPIERI, R. The reforming trajectory of the Italian educational system. Site-based managementand decentralization as a challenge for democratic discourse. Journal of Educational Administration and History, v.42, n. 1, 2010, p. 75-95.

. Jigsawing education evaluation. Pieces from the Italian New Public Management puzzle. Journal of Educational Administration and History, v. 45, n. 4, 2013, p. 306-335.

. Italian education beyond hierarchy: governance, evaluation and headship. Educational Management, Administration and Leadership, v. 42, n. 4, 2014, p. 120-139.

GUNTER, H. Leadership and the Reform of Education. Bristol: Policy Press, 2012.

KICKERT, W. Public Management Reforms in Countries with a Napoleonic State Model: France, Italy and Spain. In: POLLITT, C.; VAN THIEL, S.; HOMBURG, V. M. F. (Eds.). New Public Management in Europe. Adaptation and Alternatives. Basingstoke: Palgrave Macmillan, 2007. 
HALL, D. Drawing a veil over managerialism: leadership and the discursive disguise of the New Public Management. Journal of Educational Administration and History, v. 45, n. 3, 2013, p. 267-282.

HOOD, C. A public management for all seasons?. Public administration, v. 69, n. 1, 1991, p. 3-19.

HOOD, C.; PETERS, G. The middle aging of new public management: into the age of paradox? Journal of public administration research and theory, v. 14, n. 3, 2004, p. 267-282.

LANDRI, P. A temporary eclipse of bureaucracy. The circulation of school autonomy in Italy. Italian Journal of Sociology of Education, v. 3, n. 3, 2009, p. 76-93.

. Governing by Standards: The Fabrication of Austerity in the Italian Educational System. Education Inquiry, v. 5, n. 1, 2014, p. 1-17.

LUNT, I. Ethical issues in professional life. In: CUNNINGHAM, B. (Ed.). Exploring Professionalism. London: Institute of Education, 2008, p. 73-98.

MARTENS, K.; RUSCONI, A.; LEUZE, K. (Eds.). New Arenas of Education Governance: The Impact of International Organizations and Markets on Educational Policy Making. London: Palgrave Macmillan, 2007.

MINISTERO DELL'ECONOMIA E DELLE FINANZE. MINISTERO DELLA PUBBLICA ISTRUZIONE. Quaderno Bianco sulla Scuola. Rome. 2007. [White Paper on School].

NEAVE, G. The Evaluative State, Institutional Autonomy and Re-engineering Higher Education in Western Europe. London: Palgrave Macmillan, 2012.

NEWMAN, J. Modernizing Governance. London: Sage, 2001.

ONGARO, E. Public Management Reform and Modernization. Trajectories of Administrative Change in Italy, France, Greece, Portugal and Spain. Cheltenham: Edward Elgar, 2009.

ONGARO, E.; VALOTTI, G. Public management reform in Italy: explaining the implementation gap. International Journal of Public Sector Management, v. 21, n. 2, 2008, p. $174-204$.

PAINTER, M.; PETERS, B. G. Administrative Traditions in Comparative Perspective: Families, Groups and Hybrids. In: PAINTER, M.; PETERS, B. G. (Eds.). Tradition and Public Administration. Basingstoke: Palgrave Macmillan, 2010.

POLLITT C.; BOUCKAERT G. Public Management Reform: A Comparative Analysis. New Public Management, Governance and the Neo-Weberian State. 3. ed. Oxford: Oxford University Press, 2011.

ROSE, N. Powers of freedom. Reframing political thought. Cambridge: Cambridge University Press, 1999.

SERPIERI, R. A 'war' of discourses. The formation of educational headship in Italy. Italian Journal of Sociology of Education, v. 1, n. 1, 2009, p. 121-42. 
Jogos da verdade

VITERITTI, A. A cinderella or a princess? The Italian school between practices and reforms. Italian Journal of Sociology of Education, v. 3, n. 3, 2009, p. 10-32.

YEATMAN, A. Postmodern revisionings of the political. New York: Routledge, 1994.

WHITTY, G. Making Sense of Education Policy. London: Sage, 2002.

. Changing modes of teacher professionalism: traditional, managerial, collaborative and democratic. In: CUNNINGHAM, B. (Ed.). Exploring Professionalism. London: Institute of Education, 2008, p. 28-49.

Recebido em 21 de julho de 2015.

Aprovado em 28 de setembro de 2015.

DOI: http://dx.doi.org/10.1590/ES0101-73302015152327 